\title{
Unit Resistor Characterization for Matching-Critical Circuit Design
}

\author{
Yu Lin, Randall Geiger \\ Department of Electrical Engineering \\ Iowa State University \\ Ames, IA, USA \\ yulin, rlgeiger@iastate.edu
}

\begin{abstract}
Unit resistors are widely used in matching-critical applications. In good designs, matching performance is dominantly determined by the characteristics of the unit resistor. In this paper, a strategy for statistically characterizing the performance of unit resistors that combines the effects of contact resistance, contact size variations, sheet resistance and edge variations is introduced.
\end{abstract}

\section{INTRODUCTION}

Designers typically create a unit cell that is replicated and strategically placed at layout when designing matchingcritical circuits [1-3]. With this approach, the overall performance of the resultant circuit is strongly dependent upon the characteristics of the unit cell. To appreciate the importance of unit cell design, [4] shows that for some resistive applications, the matching performance depends on two uncorrelated parts for give total resistor area. One part is determined by overall area allocation. The other part is determined by the matching resistors implemented with unit resistors. Although many designers are aware that the performance of the unit resistor critically affects the performance of the large circuits, accurate modeling of the seemingly simple unit resistor that includes the random effects of edge variability, local random variations and contact size variations are conspicuously absent in the literature.

Considering the thin film unit resistors used in matchingcritical applications, the major variation contributors are the sheet resistance variations, contact resistance variations, contact size variations, effective length variations of the resistors and edge variations. With the feature sizes of the process decreasing, the contact resistance and contact size variations are becoming more significant and the effects of these variations can no longer be neglected in accurate modeling of unit resistors. Previous work [4] discusses the effects of the random variations of contact resistance on the resistor matching. However, it does not consider the body edge variations and the correlation between the contact size and the contact resistance.
In this paper, we will focus on the characterization of the standard deviation of the resistance of the unit resistor, including the sheet resistance variation, body edge variations and the correlation between the contact size and the contact resistance. In particular, the issues of optimization of the ratio of length and width for given unit cell area will be addressed. For simplicity, it will be assumed that resistor area, $A_{R}$, and number of unit resistors to implement the resistor, $\mathrm{N}_{\mathrm{u}}$, are fixed, i.e. the area of each unit cell, $A_{T}=A_{R} / N_{u}$ is fixed. Therefore, for overall optimal performance, the unit resistor design (or layout) should be exploited in such a way that the standard deviation of the unit cell resistance can be minimized for a given optimal area allocation scheme and for a fixed unit cell area of $\mathrm{A}_{\mathrm{T}}$.

It will also be further assumed that the only non-ideal effects are the random variations in matching critical resistors. That is, the effects of gradients, placement, and orientation of matching-critical components will not be considered but it will be assumed that known existing layout strategies including segmentation, common-centroid layouts, and peripheral dummy devices are used to manage such nonideal effects. For convenience, in the following equations, subscript " $N$ " and " $R$ " will be used to denote the nominal value and the random variations, respectively.

\section{RESISTOR MODELING}

\section{A. Contact Resistance Modeling}

A contact with area $A_{C}$ has resistance $[6,7]$ shown as

$$
\mathrm{R}_{\mathrm{C}}=\frac{\rho_{\mathrm{C}}}{\mathrm{A}_{\mathrm{C}}}
$$

where Rc is the contact resistance, $\rho_{C}$ is the resistivity of contact. For different contact shape as shown in Fig.1, (1) can be rewritten as

$$
\mathrm{R}_{\mathrm{C}}=\frac{\beta \cdot \rho_{\mathrm{C}}}{\mathrm{x}^{2}}
$$


where $\mathrm{x}$ is the length of the square contact or the diameter of the circular contact. $\beta$ is a constant but its value changes with the shape.

A straightforward analysis shows that the resistance variation of normalized $R_{C}$ can be expressed as

$$
\frac{\mathrm{R}_{\mathrm{CR}}}{\mathrm{R}_{\mathrm{CN}}}=\frac{\rho_{\mathrm{CR}}}{\rho_{\mathrm{CN}}}-\frac{2 x_{\mathrm{R}}}{\mathrm{x}_{\mathrm{N}}}
$$

Therefore the standard deviation of the normalized contact resistance is

$$
\frac{\sigma_{\frac{\mathrm{R}_{C R}}{\mathrm{R}_{\mathrm{CN}}}}^{2}}{\mathrm{R}_{\mathrm{C}}}=\sigma_{\frac{\rho_{\mathrm{RC}}}{\rho_{\mathrm{CN}}}}^{2}+4 \cdot \sigma_{\frac{\mathrm{x}_{\mathrm{R}}}{\mathrm{x}_{\mathrm{N}}}}^{2}
$$

It can be seen from (3) and (4) that when the contact size, $\mathrm{x}_{\mathrm{N}}$, decreases, the variance increases.

\section{B. Body Resistance Modeling}

It will be assumed that the sheet resistance is homogeneous throughout the region of interest and the local random variations in the sheet resistance from one point to another distinct point are uncorrelated. The resistance of a rectangular resistor shown in Fig. 2 is given by

$$
\mathrm{R}_{\mathrm{s}}=\frac{\rho \cdot \mathrm{L}}{\mathrm{W}}
$$

where $R_{S}$ is the resistance contributed by the sheet resistance of the body of the resistor. L and $\mathrm{W}$ are the length and width of the resistor.

\section{Unit Resistor Modeling}

Fig. 3 shows a unit resistor with the distance between two centers of contacts equals $\mathrm{L}_{\mathrm{C}}$ and the distance between the inner edges of two contacts equals $L, t$ is the pitch and $n$ is the number of contacts on each side of the resistor. $\mathrm{W}$ is the width of the resistor. $x$ is the dimension of the contact with its variations relate the contact size and effective length of the resistor.

It can be shown that the total resistance of this unit resistor is

$$
\mathrm{R} \approx \frac{1}{\sum_{\mathrm{k}=1}^{\mathrm{n}} \frac{1}{\mathrm{R}_{1 \mathrm{Ck}}}}+\mathrm{R}_{\mathrm{SH}}+\frac{1}{\sum_{\mathrm{k}=1}^{\mathrm{n}} \frac{1}{\mathrm{R}_{2 \mathrm{Ck}}}}
$$

where $R_{S H}$ is the resistance contributed by the sheet resistance, $R_{1 \mathrm{CK}}$ is the resistance of the $\mathrm{k}^{\text {th }}$ contact on the left hand side of the structure, and $R_{2 C k}$ is the resistance of the $k^{\text {th }}$ contact on the right hand side of the structure. Neglecting any gradient effects in the sheet resistance and the contact resistances, resistors $\mathrm{R}_{\mathrm{SH}}, \mathrm{R}_{1 \mathrm{CK}}$ and $\mathrm{R}_{2 \mathrm{CK}}$ can be expressed as with

$$
\begin{aligned}
& \mathrm{R}_{\mathrm{SH}}=\mathrm{R}_{\mathrm{SHN}}+\mathrm{R}_{\mathrm{SHR}} \\
& \mathbf{R}_{1 \mathrm{Ck}}=\mathbf{R}_{\mathrm{CN}}+\mathrm{R}_{1 \mathrm{CkR}} \mathrm{k}=1, \ldots, \mathbf{n}
\end{aligned}
$$

$$
\mathrm{R}_{2 \mathrm{Ck}}=\mathrm{R}_{\mathrm{CN}}+\mathrm{R}_{2 \mathrm{CkR}} \mathrm{k}=1, \ldots, \mathrm{n}
$$

Assuming that the random components of the contact resistances are uncorrelated, from (2), it follows that

$$
\sum_{k=1}^{n} \frac{1}{\mathrm{R}_{1 \mathrm{Ck}}} \approx \sum_{k=1}^{n} \frac{\mathrm{x}_{\mathrm{N}}^{2}}{\beta \cdot \rho_{\mathrm{CN}}}\left(1+2 \cdot \frac{\mathrm{x}_{1 \mathrm{kR}}}{\mathrm{x}_{\mathrm{N}}}-\frac{\rho_{1 \mathrm{CkR}}}{\rho_{\mathrm{CN}}}\right)
$$

From (10), the first term in (6) can be expressed as

$$
\frac{1}{\sum_{\mathrm{k}=1}^{\mathrm{n}} \frac{1}{\mathrm{R}_{1 \mathrm{Ck}}}} \approx \frac{\mathrm{R}_{\mathrm{CN}}}{\mathrm{n}}-\frac{2 \mathrm{R}_{\mathrm{CN}}}{\mathrm{n}^{2}} \sum_{\mathrm{k}=1}^{\mathrm{n}} \frac{\mathrm{x}_{1 \mathrm{kR}}}{\mathrm{x}_{\mathrm{N}}}+\frac{\mathrm{R}_{\mathrm{CN}}}{\mathrm{n}^{2}} \sum_{\mathrm{k}=1}^{\mathrm{n}} \frac{\rho_{1 \mathrm{CkR}}}{\rho_{\mathrm{CN}}}
$$

The same analysis can be applied to $\mathrm{R}_{\mathrm{C} 2 \mathrm{~K}}$. Therefore,

$$
\frac{1}{\sum_{\mathrm{k}=1}^{\mathrm{n}} \frac{1}{\mathrm{R}_{2 \mathrm{Ck}}}} \approx \frac{\mathrm{R}_{\mathrm{CN}}}{\mathrm{n}}-\frac{2 \mathrm{R}_{\mathrm{CN}}}{\mathrm{n}^{2}} \sum_{\mathrm{k}=1}^{\mathrm{n}} \frac{\mathrm{x}_{2 \mathrm{kR}}}{\mathrm{x}_{\mathrm{N}}}+\frac{\mathrm{R}_{\mathrm{CN}}}{\mathrm{n}^{2}} \sum_{\mathrm{k}=1}^{\mathrm{n}} \frac{\rho_{2 \mathrm{CkR}}}{\rho_{\mathrm{CN}}}
$$

Considering the body of the resistor shown in Fig.3, the effective length of the resistor can be expressed as

$$
\begin{aligned}
L & =L_{C}-2\left(\frac{x_{N}}{2}\right)-\frac{\sum_{k=1}^{n} x_{1 k R}+\sum_{k=1}^{n} x_{2 k R}}{n} \\
& =L_{N}-\frac{\sum_{k=1}^{n} x_{1 k R}+\sum_{k=1}^{n} x_{2 k R}}{n}
\end{aligned}
$$

where $L_{N}$ is the nominal value of $L$. Since the random variation of $L_{C}$ is very small compared to the variation of $x$, we assume the nominal value of $\mathrm{L}_{\mathrm{C}}$ is still $\mathrm{L}_{\mathrm{C}}$.

The resistance contributed by the sheet resistance of the resistor body can be derived from (5) and (13) and expressed as

$$
\begin{aligned}
& \mathrm{R}_{\mathrm{SH}} \approx \mathrm{R}_{\mathrm{SHN}}+\mathrm{R}_{\mathrm{SHN}} \cdot \frac{\rho_{\mathrm{R}}}{\rho_{\mathrm{N}}}-\mathrm{R}_{\mathrm{SHN}} \cdot \frac{\mathrm{W}_{\mathrm{R}}}{\mathrm{W}_{\mathrm{N}}}- \\
& \mathrm{R}_{\mathrm{SHN}} \cdot\left(\frac{\mathrm{x}_{\mathrm{N}}}{\mathrm{n} \cdot \mathrm{L}_{\mathrm{N}}}\right) \frac{\sum_{\mathrm{k}=1}^{\mathrm{n}} \mathrm{x}_{1 \mathrm{kR}}}{\mathrm{x}_{\mathrm{N}}}-\mathrm{R}_{\mathrm{SHN}} \cdot\left(\frac{\mathrm{X}_{\mathrm{N}}}{\mathrm{n} \cdot \mathrm{L}_{\mathrm{N}}}\right) \frac{\sum_{\mathrm{k}=1}^{\mathrm{n}} \mathrm{x}_{2 \mathrm{kR}}}{\mathrm{x}_{\mathrm{N}}}
\end{aligned}
$$

From (11), (12) and (14), it follows that

$$
\mathrm{R}_{\mathrm{N}}=\frac{2 \mathrm{R}_{\mathrm{CN}}}{\mathbf{n}}+\mathrm{R}_{\mathrm{SHN}}
$$

and

$$
\begin{aligned}
& \mathrm{R}_{\mathrm{R}} \approx\left(-\frac{2 \mathrm{R}_{\mathrm{CN}}}{\mathrm{n}^{2}}-\mathrm{R}_{\mathrm{SHN}} \cdot\left(\frac{\mathrm{X}_{\mathrm{N}}}{\mathrm{n} \cdot \mathrm{L}_{\mathrm{N}}}\right)\right) \cdot\left(\sum_{\mathrm{k}=1}^{\mathrm{n}} \frac{\mathrm{x}_{1 \mathrm{kR}}}{\mathrm{X}_{\mathrm{N}}}+\sum_{\mathrm{k}=1}^{\mathrm{n}} \frac{\mathrm{x}_{2 \mathrm{kR}}}{\mathrm{X}_{\mathrm{N}}}\right)+ \\
& \frac{\mathrm{R}_{\mathrm{CN}}}{\mathrm{n}^{2}} \cdot\left(\sum_{\mathrm{k}=1}^{\mathrm{n}} \frac{\rho_{1 \mathrm{CkR}}}{\rho_{\mathrm{CN}}}+\sum_{\mathrm{k}=1}^{\mathrm{n}} \frac{\rho_{2 \mathrm{CkR}}}{\rho_{\mathrm{CN}}}\right)+\mathrm{R}_{\mathrm{SHN}} \cdot \frac{\rho_{\mathrm{R}}}{\rho_{\mathrm{N}}}-\mathrm{R}_{\mathrm{SHN}} \cdot \frac{\mathrm{W}_{\mathrm{R}}}{\mathrm{W}_{\mathrm{N}}}
\end{aligned}
$$




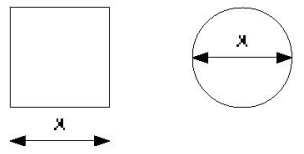

Fig. 1 Square and circular contacts

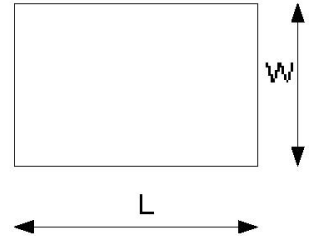

Fig. 2 Body of resistor with length $L$ and width $W$

Edge variations can be modeled by allowing the length variation inversely proportional to width and width variation inversely proportional to length $[5,8,9]$. Here, we assume the random variation of $\mathrm{x}$ is inversely proportional to $\mathrm{x}_{\mathrm{N}}$. Resistivity variance can be modeled by allowing it inversely proportional to the area [8]. Therefore, it will be assumed that

$$
\begin{aligned}
& \sigma_{\mathrm{X}_{1 \mathrm{kR}}}^{2}=\sigma_{\mathrm{X}_{2 \mathrm{kR}}}^{2}=\sigma_{\mathrm{X}_{\mathrm{kR}}}^{2}=\frac{\alpha_{1}}{\mathrm{X}_{\mathrm{N}}} \\
& \sigma_{\rho_{1 \mathrm{CkR}}}^{2}=\sigma_{\rho_{2 \mathrm{CkR}}}^{2}=\sigma_{\rho_{\mathrm{CkR}}}^{2}=\frac{\alpha_{2}}{\mathrm{X}_{\mathrm{N}}^{2}} \\
& \sigma_{\rho}^{2}=\frac{\alpha_{3}}{\mathrm{~L}_{\mathrm{N}} \mathrm{W}_{\mathrm{N}}} \text { and } \sigma_{\mathrm{W}}^{2}=\frac{\alpha_{4}}{\mathrm{~L}_{\mathrm{N}}}
\end{aligned}
$$

where $\alpha_{1}, \alpha_{2}, \alpha_{3}, \alpha_{4}$ are the process parameters that characterize the standard deviation of the $x$, contact resistivity, sheet resistance and width of the resistor. A straightforward analysis shows that the resistance variance of the resistor is

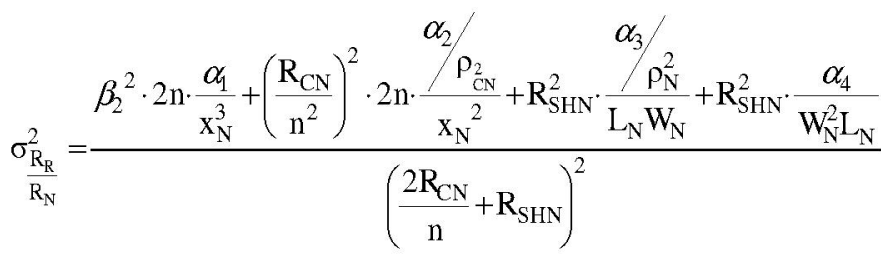

where $\beta_{2}=-\frac{2 \mathrm{R}_{\mathrm{CN}}}{\mathrm{n}^{2}}-\mathrm{R}_{\mathrm{SHN}} \cdot\left(\frac{\mathrm{x}_{\mathrm{N}}}{\mathrm{n} \cdot \mathrm{L}_{\mathrm{N}}}\right)$

The number of contacts on each side of resistor can be determined by $n=W / t$. It will be shown that the unit resistor area $A_{T}$ and the ratio of length and width, $m$, can be expressed as

$$
\mathrm{A}_{\mathrm{T}}=\mathrm{L}_{\mathrm{N}} \mathrm{W}_{\mathrm{N}}, \quad \mathrm{m}=\frac{\mathrm{L}_{\mathrm{N}}}{\mathrm{W}_{\mathrm{N}}}
$$

From (21), it can be derived that

$$
\mathrm{W}_{\mathrm{N}}=\sqrt{\frac{\mathrm{A}_{\mathrm{T}}}{m}}
$$

From (21), (20) can be rewritten as

$$
\sigma_{\frac{R_{R}}{R_{N}}}^{2}=\frac{\frac{\left(2 R_{C N} \cdot t+\rho_{N} x_{N}\right)^{2} \cdot 2 \cdot \alpha_{1} \cdot t}{x_{N}^{3} \cdot W_{N}^{3}}+\frac{2 \beta \alpha_{2} t^{3}}{W_{N}^{3}}+\left(\frac{\alpha_{3}}{A_{T}}\right) m^{2}+\frac{\alpha_{4} \rho_{N} \mathrm{~m}}{W_{N}^{3}}}{\left(\frac{2 R_{C N} \cdot t}{W_{N}}+\rho_{N} \cdot m\right)^{2}}
$$

Insert (22) into (23), it can be obtained that

$$
\begin{aligned}
\sigma_{\frac{\mathrm{R}_{\mathrm{R}}}{\mathrm{R}_{\mathrm{N}}}}^{2} & =\frac{\left(\frac{\left(2 \mathrm{R}_{\mathrm{CN}} \cdot \mathrm{t}+\rho_{\mathrm{N}} \mathrm{x}_{\mathrm{N}}\right)^{2} \cdot 2 \cdot \alpha_{1} \cdot \mathrm{t}}{\mathrm{x}_{\mathrm{N}}^{3} \mathrm{~A}_{\mathrm{T}}^{1.5}}+\frac{2 \beta \alpha_{2} \mathrm{t}^{3}}{\mathrm{~A}_{\mathrm{T}}^{1.5}}\right) \mathrm{m}^{0.5}+\left(\frac{\alpha_{3}}{\mathrm{~A}_{\mathrm{T}}}\right) \mathrm{m}+\left(\frac{\alpha_{4} \rho_{\mathrm{N}}}{\mathrm{A}_{\mathrm{T}}^{1.5}}\right) \mathrm{m}^{1.5}}{\left(\left(\frac{2 \mathrm{R}_{\mathrm{CN}} \cdot \mathrm{t}}{\mathrm{A}_{\mathrm{T}}^{0.5}}\right)+\rho_{\mathrm{N}} \cdot \mathrm{m}^{0.5}\right)^{2}} \\
& =\frac{\mathrm{B}_{1} \mathrm{~m}^{0.5}+\mathrm{B}_{2} \mathrm{~m}+\mathrm{B}_{3} \mathrm{~m}^{1.5}}{\left(\mathrm{~B}_{4}+\mathrm{B}_{5} \mathrm{~m}^{0.5}\right)^{2}}
\end{aligned}
$$

where $\mathrm{B}_{1}=\left(\frac{\left(2 \mathrm{R}_{\mathrm{CN}} \cdot \mathrm{t}+\rho_{\mathrm{N}} \mathrm{x}_{\mathrm{N}}\right)^{2} \cdot 2 \cdot \alpha_{1} \cdot \mathrm{t}}{\mathrm{x}_{\mathrm{N}}^{3} \mathrm{~A}_{\mathrm{T}}^{1.5}}+\frac{2 \beta \cdot \alpha_{2} \mathrm{t}^{3}}{\mathrm{~A}_{\mathrm{T}}^{1.5}}\right)$

$\mathrm{B}_{2}=\left(\frac{\alpha_{3}}{\mathrm{~A}_{\mathrm{T}}}\right), \quad \mathrm{B}_{3}=\left(\frac{\alpha_{4} \cdot \rho_{\mathrm{N}}}{\mathrm{A}_{\mathrm{T}}^{1.5}}\right), \quad \mathrm{B}_{4}=\left(\frac{2 \mathrm{R}_{\mathrm{CN}} \cdot \mathrm{t}}{\mathrm{A}_{\mathrm{T}}^{0.5}}\right), \quad \mathrm{B}_{5}=\rho_{\mathrm{N}}$

These parameters are constants for a given process and given resistor area $A_{T}$.

\section{RESULTS AND DISCUSSION}

Equation (24) shows the relationship between the variance of the unit cell resistance and the $\mathrm{L} / \mathrm{W}$ ratio for given unit resistor area and given type of resistor. It can be shown that the $\mathrm{L} / \mathrm{W}$ dependence of resistance variance is depend upon the relative values of $B_{1}, B_{2}, B_{3}, B_{4}$ and $B_{5}$ which are eventually determined by the process parameters and unit resistor area $\mathrm{A}_{\mathrm{T}}$. For different process and different type of resistors, these parameters may be very different. Fortumately, after varying all the process parameters, it can be observed that the shape of this dependency will not be very much different from the following two examples shown in Fig.4. In these examples, $A_{T}$ is $100 \mu \mathrm{m}^{2}$, and the " $\mathrm{B}$ " values are calculated by assuming $\alpha_{1}=10 \mu \mathrm{m}^{3}, \alpha_{2}=10 \Omega^{2} \mu \mathrm{m}^{6}$, $\alpha_{3}=10 \Omega^{2} \mu \mathrm{m}^{2}, \mathrm{R}_{\mathrm{CN}}=10 \Omega, \mathrm{X}_{\mathrm{N}}=0.3 \mu \mathrm{m}, \rho_{\mathrm{N}}=10 \Omega / \mathrm{square}$, and $\beta=0.78$ (circular contact). It is also assumed that $\alpha_{4}=100 \mu \mathrm{m}^{3}$ in Fig.4(a) and $\alpha_{4}=10 \mu \mathrm{m}^{3}$ in Fig.4(b).

In Fig.4 (a), the variance of resistance decreases rapidly with the increase of $\mathrm{m}$. After reaching a minimum value, it starts to increase with the increase of $\mathrm{m}$. The $\mathrm{m}$ value corresponding to the minimum variance should be used for 
the unit resistor design. In contrast to Fig.4(a), the variance of resistance in Fig. 4(b) changes very slowly after $m$ approaches to a certain value. Therefore, we can choose $\mathrm{m}$ value in the insensitive flat region.

The only difference between Fig.4(a) and Fig.4(b) is the value of $\alpha_{4}$. From (19) and (24), it can be observed that $\alpha_{4}$ represents the body width variation of the resistor. For given examples, larger $\alpha_{4}$ indicates large width variation. It can shown from these two plots that when $\alpha_{4}$ is large, the contribution of the "m.1." in (24) term is more significant when $m$ is large.

In real design, for a given process, but different types of resistor, these " $\alpha$ " values may be different. For a given type of resistor, but different processes, these values will also be different. Therefore, the $\mathrm{m}$ dependence of corresponding resistance variance will be different. To determine the optimal geometries for a given process with given type of resistor and unit resistor area $A_{T}$, the exact values of process parameters are needed. For practical design, there are upper and lower limits for the length and width of resistor, which consequently affect the lower and upper bound of $\mathrm{L} / \mathrm{W}$ ratio and needs to be considered for determining the optimal geometries.

\section{CONCLUSIONS}

A resistor model includes the effects of variations in the sheet resistance of the body, body edge variations, and the correlation between contact size, contact resistance, and effective length of the resistor has been introduced. With this model, optimum or near optimum unit resistor geometries that are needed for matching critical applications can be developed.

\section{REFERENCES}

[1] A. Hastings, The Art of Analog Layout, Prentice Call, New Jersey, 2000 .

[2] A.Grebene, Bipolar and MOS Analog Integrated Circuit Design, Wiley, New York, 1994.

[3] M.Ismail and T. Fiez, Analog VLSI Signal and Information Processing, McGraw Hill, New York, 1994.

[4] Y. Lin, D. Chen and R. Geiger, "Yield Enhancement with Optimal Area Allocation for Ratio-Critical Analog Circuits", to appear in IEEE Trans. on Circuits and Systems I

[5] J. Shyu, G.Temes and F.Krummenacher, "Random Error Effects in Matched MOS Capacitors and Current sources", IEEE J. Solid State Circuits, Vol. sc-19, pp. 948-955, Dec. 1984.

[6] T. Hamamoto, T. Ozaki, M. Aoki, Y. Ishibashi, "Measurement of OCntact reisstance Distribtuion Using a 4k- Contacts Array," IEEE Trans. On Semiconductor Manufacotring, Vol. 9, No.1, pp.9-14, Feb, 1996

[7] S. Proctor, L. Linholm, J. Mazer, " Direct Measurements of Interfacial Contact Resistnace, End Contact Resistance, and Iterfacial Contact Layer Uniformity", IEEE Trans. On Electron Devices, Vol. ED-30, No,.11, pp1535-1542, Nov.1983

[8] P.Drennan,"Diffused Resistor Mismatch Modeling and Characterization", Bipolar/BiCMOS Circuits and Technology Meeting, pp27-30, Sep.1999
[9] J.Shyu, G.Temes, K.Yao, "Random errors in MOS capacitors", IEEE Journal of Solid-State Circuits, Vol. 17,Issue 6, pp.1070 - 1076, Dec 1982

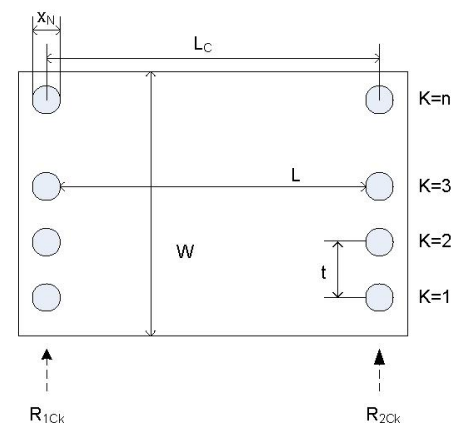

Fig.3 Unit resistor

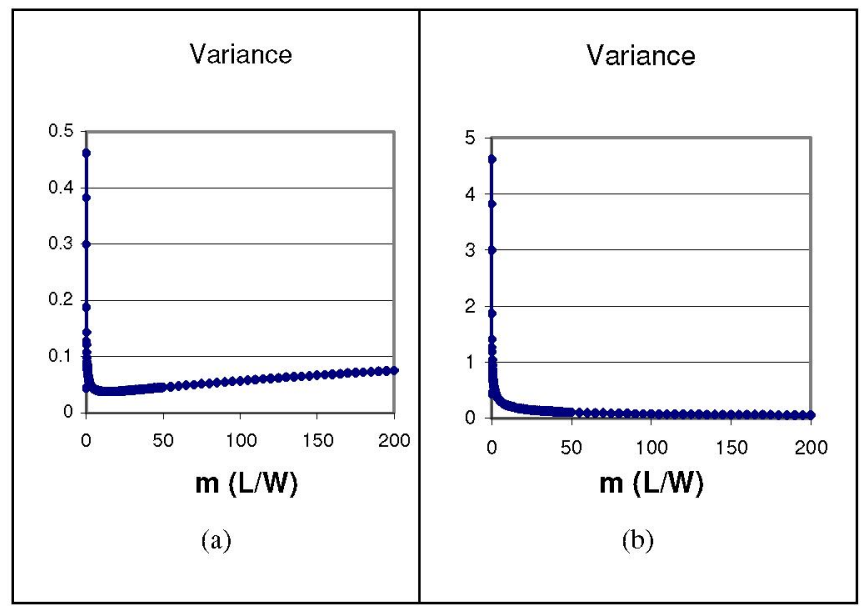

Fig.4 Variance of $\left(R_{R} / R_{N}\right)$ vs. $m$ of two examples (a) $\alpha_{4}=100 \mu \mathrm{m}^{3}$ (b) $\alpha_{4}=10 \mu \mathrm{m}^{3}$ 